\title{
PENDIDIKAN MORAL DALAM PERSPEKTIF PENDIDIKAN ISLAM
}

\author{
Mulya Hasanah \\ SD Muhammadiyah Sidoarum \\ Email : mulya.hasanah@yahoo.co.id
}

\begin{abstract}
ABSTRAK
Pendidikan Moral dalam Perspektif Pendidikan Islam adalah suatu gejala sosial dalam masyarakat yang bertentangan dengan ciri-ciri atau nilai budaya, serta nilai keagamaan dalam masyarakat sekolah. Artikel ini bertujuan mendeskripsikan terkait dengan nilai norma dalam pendidikan moral pada lingkungan masyarakat dan seberapa pentingnya pendidikan moral pada lingkungan masyarakat sekolah. Subjek dalam penelitian ini menggunakan berbagai macam literatur yang terdiri dari buku dan hasil penelitian orang lain yang digunakan dan dikaji secara ilmiah. Studi ini menggunakan pendekatan kualitatif dengan teknik study literature. Berdasarkan hasil analisis data study literature diperoleh hasil penelitian yang menunjukkan bahwa dari berbagai sudut pandang teori pendidikan moral yang sesuai dengan perspektif pendidikan islam itu perlu diterapkan dalam sekolah-sekolah, guna untuk membangun nilai-nilai norma mengenai pendidikan moral yang sesuai dengan ciri ataupun nilai budaya serta nilai keagamaan dalam masyarakat lingkungan sekolah melalui pandangan sufisme.
\end{abstract}

Kata Kunci: Pendidikan Moral; Pendidikan Agama; Nilai Norma

\begin{abstract}
:
Moral Education in Islamic Education Perspective is a social phenomenon in society that is contrary to cultural traits or values, as well as religious values in the school community. This article aims to describe the values associated with norms in


Al-Tarbawi Al-Haditsah: Jurnal Pendidikan Islam

Vol. 3, No. 2, Desember 2018

moral education in the community environment and how important moral education in the school community environment. Subjects in this study using a variety of literature consisting of books and research results of others who used and studied scientifically. This research uses qualitative approach with study literature technique. Based on the results of the analysis of study literature data obtained research results indicate that from various perspectives of moral education theory in accordance with the perspective of Islamic education is necessary, in order to establish norms of moral education in accordance with the characteristics or cultural values and religious values in society school environment through the view of Sufism.

Keywords: Moral Education; Religious Education; Norma Value

\section{A. PENDAHULUAN}

Pada masa sekarang, kadar permasalahan dalam masyarakat lingkungan sekolah sering kalai kita temukan gejala sosial yang merupakan suatu keadaan dalam lingkungan yang bertentangan dengan ciri-ciri ataupun nilai budaya, serta nilai keagamaan dalam lingkungan masyarakat, khususnya lingkungan sekolah. Ketika masyarakat berfikir mengenai moralitas merupakan suatu perubahan yang terus menerus mengalami perubahan yang relatif, dimana individu tersebut bergantung terhadap situasi lingkungan serta bersifat personal. Maka pendidikan ini sangat berperan penting dalam pembentukan generasi muda bangsa guna memiliki nilai-nilai pendidikan yang baik. Hal ini merupakan tugas pendidik guna menciptakan generasi-generasi bangsa yang baik, berakhlak bagus, dan budi pekerti sesuai dengan nilai-nilai norma keagamaan.

Pendidikan moral bukan merupakan suatu gagasan baru, melainkan pendidikan ini sama tuanya dengan pendidikan itu sendiri. Sepanjang sejarah di negara-negara yang ada di seluruh dunia, pendidikan memiliki dua tujuan besar, 


\section{Al-Tarbawi Al-Haditsah: Jurnal Pendidikan Islam}

Vol. 3, No. 2, Desember 2018

yaitu membentuk anak-anak menjadi pintar serta membantu mereka menjadi baik. ${ }^{1}$ Pada dunia pendidikan, adapun yang menyebabkan pendidikan moral mengalami sebuah kemunduran yaitu diakibatkan dari budaya moral yang ada pada dunia pendidikan ataupun sekolah itu sendiri. Hal ini dikarenakan perbedaan dari tingkat penerapan peraturan pada tingkat moral peserta didik pada lingkungan sekolah, maka berbeda-beda pula perilaku moral yang ditimbulkan pada diri mereka yang mereka pahami.

Selain itu pula, perilaku moral yang ditentukan oleh kecenderungan bertindak itu dimotivasi oleh sifat perilaku dan kebiasaan seseorang. Dengan ini, seseorang yang berperilaku amoral lebih disebabkan oleh faktor-faktor situasional dan tidak dipungkiri bahwa pembentukan moralitas itu juga terbentuk tidak hanya dalam dunia pendidikan. Melainkan di rumah, yaitu peran pendidikan dari orang tua dan lingkungan yangn juga berpengaruh. ${ }^{2}$ Dengan ini, peran dunia pendidikan yaitu guna membantu mengajarkan nilai-nilai moral yang baik agar semakin tinggi dan baik pula tingkat perilaku moral pada diri seseorang. Salah satu bagian dari pendidikan moral di Indonesia adalah menolong generasi muda untuk memahami tradisi moral masyarakat Indonesia, karena penurunan moral pada masa remaja dewasa ini menjadikan pendidikan moral itu sendiri menjadi penting supaya nantinya anak-anak didik menjadi manusia yang bermartabat, menjadi warga bangsa yang berkarakter sesuai dengan nilai-nilai leluhur bangsa dan agama. ${ }^{3}$

Hasil riset ini bertujuan untuk memberikan informasi terkait nilai norma dalam pendidikan moral pada lingkungan masyarakat sekolahan dan seberapa pentingnya pendidikan moral pada lingkungan masyarakat sekolahan.

\section{B. PEMBAHASAN}

\section{Pendidikan Moral}

\footnotetext{
${ }^{1}$ Thomas Lickona, Pendidikan Karakter Panduan Lengkap Mendidik Siswa Menjadi Pintar dan Baik (Bandung: Nusa Media, 2013), 6.

${ }^{2}$ Sjarkawi, Pembentukan Keperibadian Anak (Peran Moral, Intelektual, Emosional, dan Sebagai Wujud Integritas Membangun Jati Diri (Jakarta: Bumi Aksara, 2011), 37-38.

${ }^{3}$ Darmiyati Zuchdi, Humanisasi Pendidikan (Menemukan kembali Pendidikan yang Manusiawi) (Jakarta: Bumi Aksara, 2009), 76-77.
} 


\section{Al-Tarbawi Al-Haditsah: Jurnal Pendidikan Islam}

Vol. 3, No. 2, Desember 2018

Menurut UU Sistem Pendidikan Nasional No. 20 Tahun 2003 bahwa pendidikan adalah usaha sadar dan terencana untuk mewujudkan suasana belajar dan proses pembelajaran agar peserta didik secara aktif mengembangkan potensi dirinya untuk memiliki kekuatan spiritual keagamaan, pengendalian diri, kepribadian, kecerdasan, akhlak mulia, serta keterampilan yang diperlukan dirinya, masyarakat, bangsa, dan Negara. ${ }^{4}$

Pemahaman mengenai konsep moralitas; apa yang dimaksud moralitas; adalah titik awal dari pendidikan moral. ${ }^{5}$ Secara etimologis, kata moral berasal dari kata mos dalam bahasa Latin, bentuk jamaknya mores yang artinya adalah tata cara atau adat istiadat. Terkait dengtan wacana pendidikan moral dalam sistem pendidikan formal (persekolahan), kiranya relevan untuk diungkapkan kembali "paradigm lama" tentang pendidikan, yakni pendidikan sebagai pewarisan dan pelestarian nilai-nilai. Paradigm semacam itu dikemukakan Bourdieu dalam Karabel and Halsey:

By traditionally defining the educational system as the group of institutional or routine mechanism by means of which is operated what Durkheim calls "the conservation of a culture inherited from the past", i.e. the transmission from generation to generation of accumulated information, classical theories tend to associate the fuction of cultural reproduction proper to all educational system from their function of social reproduction.

Dengan mendeskripsikan secara tradisional maka pewarisan dan pelestarian nilai-nilai budaya warisan masa lalu tersebut terutama menyangkut mengenai nilai-nilai moral dan adat istiadat. Pada masa silam, pendidikan moral pada mulanya dipandang sebagai inti dan wajah pendidikan itu sendiri. ${ }^{6}$ Hal itu maka menjadikan pentingnya pendidikan moral yang harus ditanamkan pada anak-anak didik guna mencetak generasi yang baik bagi generasi bangsa kedepannya.

4 Undang-Undang RI Nomer 31 Tahun 2003 tentang Undang-undang Sisdiknas dan Undang-undang Guru dan Dosen

5 Darmiyati Zuchdi, Pendekatan Pendidikan Nilai Secara Komprehensif Sebagai Suatu Alternatif Pembentukan Akhlak Bangsa (Makalah Seminar) (Yogyakarta: Lembaga Penelitian UNY, 2001), 6.

${ }^{6}$ Karabel and Halsey, editors, Power and Ideology in Education (New York: Oxford University Press, 1977), 488. 
Pendidikan moral ternyata juga masih memperoleh perhatian di Negara-negara Barat, khususnya Amerika Serikat, yang dikenal longgar dalam persoalan moral. Menurut Kirschenbaum sejak tahun 1990 telah dikembangkan pendidikan moral yang mengajarkan nilai-nilai tradisional dengan adanya dukungan para orang tua, pemuka agama, guru, dan politisi. ${ }^{7}$ Hal ini membuktikan bahwa meningkatnya perhatian terhadap pendidikan moral itu disebabkan karena ketidakmampuan negara dalam mengatasi masalah minimum keras, kriminilitas, kekerasan, disintegrasi keluarga, meningkatnya jumlah remaja yang bunuh diri dan remaja puteri yang mengandung, mengakibatkan menurunnya tanggung jawab masyarakat, tumbuhnya pertentangan rasial, serta tidak terkendalinya jumlah skandal pada tahun 1980-an. ${ }^{8}$ Maka pendidikan moral yang terkait dengan etika dalam agamanya sangat diperlukan dalam mengatasi permasalahan yang ada sehingga memberikan arahan atau petunjuk bagi seseorang kearah yang lebih baik.

\section{Pendidikan Moral Menurut Pandangan Islam}

Ada istilah yang senantiasa disejajarkan ketika seseorang membicarakan tentang etika sosial manusia. Di antara istilah-sitilah itu adalah moral, etika, dan akhlak. Rachmat Djatnika dalam bukunya yang berjudul Sistem Ethika Islami (Akhlak Mulia) mengatakan bahwa sinonim dari akhlak adalah etika dan moral. ${ }^{9}$ Seperti yang telah dijelaskan diatas bahwa pengertian dari moral dipakai untuk menunjuk kepada suatu tindakan atau perbuatan yang sesuai dengan ide-ide umum yang berlaku dalam suatu komunitas atau lingkungan tertentu.Sementara itu dikatakan oleh Karl Barth, kata "etika" yang berasal dari kata "ethos" adalah sebanding dengan kata "moral" dari kata "mos". Kedua-duanya merupakan filsafat tentang adat kebiasaan. Di sini Karl Barth secara tegas memberikan penjajaran yang sama antara kata etika dan moral.

Adapun hadits yang berkaitan mengenai moral adalah sebagai berikut:

\footnotetext{
${ }^{7}$ Darmayanti Zuchdi, Ibid., 2001, 1-2.

8 Ibid.

${ }^{9}$ Rachmat Djatnika, Sistem Ethika Islam (Akhlak Mulia) (Bandung: Panjimas, 1996), 26.
} 


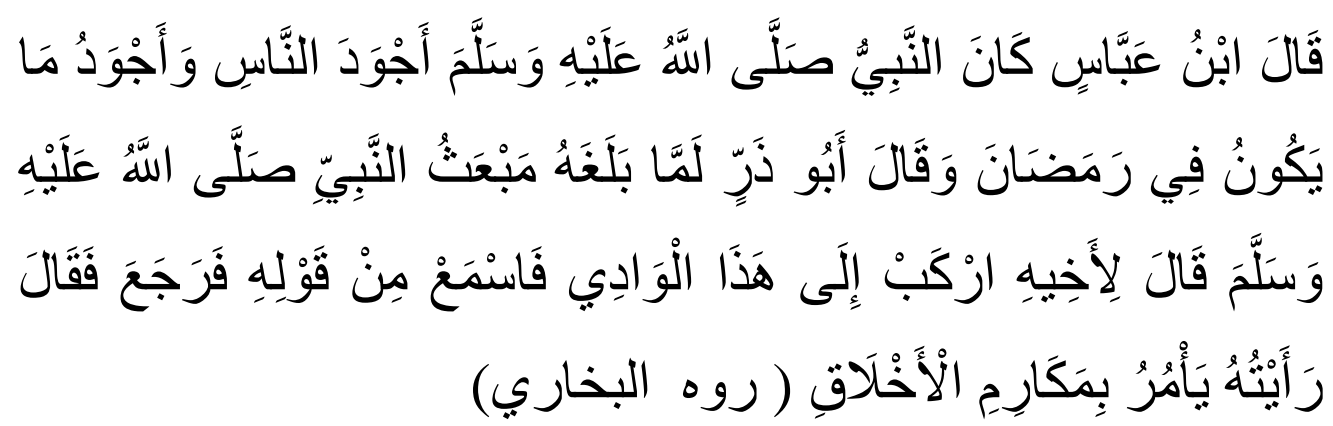

Ibnu 'Abbas meriwayatkan bahwa Nabi saw adalah orang paling dermawan. Beliau menjadi lebih dermawan lagi di bulan Ramadhan. Dan Abu Dzar berkata bahwa ketika ia mendengar kedatangan Nabi Muhammad Alaihisalam, ia berkata kepada saudara laki-lakinya, "Pergilah ke lembah itu dan dengarkan apa yang ia katakan." Saudaranya kembali dan berkata, "Aku melihat ia memerintahkan orang-orang kepada moral dan perilaku (akhlak) yang paling mulia." (HR. Bukhari)

Dari hadits diatas, kita dapat mengetahui bahwa Rasulullah SA memerintahkan kita untuk berakhlak mulia. Adapun terkait dengan moralitas ataupun akhlak manusia al-Ghazali membuat pembedaan dengan menempatkan manusia pada empat tingkatan. Pertama, terdiri dari orang-orang yang lengah, yang tidak dapat membedakan kebenaran dengan yang palsu atau antara yang baik dengan yang buruk. Nafsu jasmani kelompok ini bertambah kuat, karena tidak memperturutkannya. Kedua, terdiri dari orang yang tahu betul tentang keburukan dari tingkah laku yang buruk, tetapi tidak menjauhkan diri dari perbuatan itu. Mereka tidak dapat meninggalkan perbuatan itu disebabkan adanya kenikmatan yang dirasakan dari perbuatana itu. Ketiga, orang-orang yang merasa bahwa perbuatan buruk yang dilakukannya adalah sebagai perbuatan yang benar dan baik. Pembenaran yang demikian dapat berasal dari adanya kesepakatan kolektif yang berupa adat kebiasaan suatu masyarakat. Dengan demikian orang-orang ini melakukan perbuatan tercelanya dengan leluasa dan tanpa merasa berdosa. 


\section{Al-Tarbawi Al-Haditsah: Jurnal Pendidikan Islam}

Vol. 3, No. 2, Desember 2018

Keempat, orang-orang yang dengan sengaja melakukan perbuatan buruk atas dasar keyakinannya. ${ }^{10}$

Dalam rangka tujuan membangun akhlak yang baik dalam diri manusia, al-Ghazali menyarankan melatihnya ataupun membangunya sejak usia dini. Pribahasa Arab mengatakan bahwa pembelajaran sejak kecil seperti mengukir tulisan di atas batu. Jadi Orang tua itu bertanggung jawab atas diri anak-anaknya. Bahkan ia mengatakan agar seorang anak diasuh dan disusukan oleh seorang perempuan yang shalehah agar mengarahkan pada tabiat yang baik dan sebaliknya. Setelah memasuki usia cerdas (tamyiz), seorang anak harus diperkenalkan dengan nilai-nilai kebaikan yang diajarkan dalam Islam. Seperti disebutkan di atas, proses ini dapat dilakukan melalui pembiasaan dan melalui proses logis atas setiap perbuatan, baik yang menyangkut perbuatan baik atau buruk. Melakukan identifikasi secara rasional atas setiap akibat dari perbuatan baik dan buruk bagi kehidupan diri dan sosialnya. ${ }^{11}$

Ketika pikirana logis itu menyertai perbuatan seseorang, Insya Allah setiap orang akan berpikir lebih dahulu dalam melakukan perbuatannya. Apakah perbuatan itu berimplikasi buruk, baik yang berupa munculnya prasangka buruk terhadap dirinya, atau secara langsung berakibat buruk terhadap orang lain. Dengan kata lain terdapat kontrol yang terus menerus dari diri seseorang ketika akan melakukan suatu perbuatan tertentu. Seseorang akan memiliki kesadaran sejati dan pertimbangan yang matang terhadap implikasi-implikasi dari setiap perbuatannya.

Menurut Hogan dan Busch peningkatan pertimbangan mengenai moral pada diri seseorang yang dirancang secara sengaja melalui pendidikan di sekolah maupun dirumah, dapat membantu pembentukan kepribadian seseorang dikarenakan dengan terbentuknya pertimbangan moral pada dirinya maka seseorang akan berperilaku (behavior) sesuai dengan cara berfikir moral (moral

${ }^{10}$ Abdul Quasem, Etika Al-Ghazali (Bandung:Penerbit Pustaka, 1988), 92.

${ }^{11}$ Ibid. 


\section{Al-Tarbawi Al-Haditsah: Jurnal Pendidikan Islam}

Vol. 3, No. 2, Desember 2018

thinking) yang ada padanya. Perilaku yang ada pada diri seseorang berlandas pada pertimbangan-pertimbangan kognitifnya. ${ }^{12}$

Dalam konteks kehidupan global yang semakin transparan dan penuh kompetisi, nilai agama dan moralitas merupakan benteng agar setiap individu tidak terjerumus dalam praktik kesewenag-wenangan dan ketidak adilan. Pendidikan agama dan moral merupakan pedoman sangat penting bagi dalam proses belajar mengajar sebagai salah satu antisipasi agar anak-anak didik kita terhindar hal-hal yang bertentangan dengan agama di era globalisasi saat ini. Dikatakan, dengan kuatnya pendidikan agama akan menciptakan generasi yang bermoral dan berkualitas. Kondisi itulah yang saat ini ditanamkan Yayasan Pendidikan. Harapannya, sehingga melahirkan generasi-generasi yang berkualitas dengan cirinya iman, ilmu dan amal.

Dalam membentuk generasi-generasi yang seutuhnya tentunya ada unsur-unsur yang tidak dapat terpisahkan dalam pendidikan yaitu pengakuan dan penghargaan akan nilai-nilai kemanusiaaan. Pengakuan dan penghargaan akan tumbuh manakala seseorang itu ditanamkan nilai-nilai moral sejak usia dini. Niali-nilai moral ini pertama-tama muncul bukan melalui teori-teori atau konsep melainkan melalui latihan atau pengalaman konkrit yang langsung dirasakan anak-anak dalam pendidikan yaitu di sekolah. ${ }^{13}$

Pendidikan moral ditujukan untuk memagari seseorang dari hal perbuatan buruk atau perbuatan tidak baik yang tidak sesuai dengan norma-norma yang ada dalam pendidikan, bermasyarakat, berbangsa, dan bernegara. Maka tinggi dan rendahnya tingkat pertimbangan moral seseorang menentukan baik dan tidaknya perilaku atau tindakan moralitas dalam bermasyarakat. Pada masa sekarang ini, kita dapati bahwa kemunduran tingkat moral seseorang sangatlah miris, contoh dalam dunia pendidikan sendiri ditemui maraknya penggunaan obat-obatan terlarang, tidak jarang hal tersebut merambah keanak-anak dikalangan pendidikan, sering

${ }^{12}$ Sjarkawi, Ibid., 26.

13 Fatima Ibda, Pendidikan Moral Anak Melalui Pengajaran Bidang Studi PPKn dan Pendidikan Agama (Jurnal Ilmiah Didaktika, vol. XII no.2 Februari 2012), hal 345-346. 


\section{Al-Tarbawi Al-Haditsah: Jurnal Pendidikan Islam}

Vol. 3, No. 2, Desember 2018

terjadi bentrokan yang dasanya sepele menjadi hal yang besar, dan terjadinya seks bebas di kalangan anak-anak, kebanyakan remaja.

Adapun dalam penelitian yang dilakukan oleh Fahrudin mengenai faktor-faktor yang menyebabkan kemerosotan moral pada anak-anak, diantaranya: (1) kurang ditanamkannya nilai-nilai keimanan pada ana-anak dari dini, (2) lingkungan masyarakat yang kurang baik, (3) pendidikan moral yang tidak berjalan sebagaimana mestinya, baik di keluarga, sekolah, dan masyarakat, (4) suasana rumah tangga yang kurang harmonis, (5) banyak diperkenalkannya obat-obat terlarang dan alat-alat anti hamil, (6) banyak tulis-tulisan, gambar-gambar, siaran-siaran yang tidak sejalan dengan nilai-nilai moral, (7) kurang adanya bimbingan dalam mengisi waktu luang dengan cara baik yang membawa kepada pembinaan moral, (8) kurangnya markas-markas bimbingan dan penyuluhan bagi anak-anak. ${ }^{14}$

Dari faktor-faktor di atas terdapat dua (2) point inti yang sangat berperan penting dari kemerosotan moral yang terjadi pada anak-anak. Diantaranya yaitu, pertama dari keluarga dan yang kedua dari lingkungan dimana anak bersosialisasi. Dua faktor ini adalah faktor dimana anak mendapatkan sumber-sumber perlakuan yang nantinya akan dicontohkannya bagi dirinya sendiri, baik itu perlakuan yang baik ataupun perlakuan yang buruk. Sehingga perlunya bimbingan atu pembinaan seorang anak guna membedakan mana moral yang baik dan mana moral yang buruk yang nantinya dapat terarahkan kepada moral yang baik. Maka harus diperlukannya pendidikan, yang nantinya pendidikan ini adalah sebagai kunci untuk perbaikan diri, maka pendidikan moral khususnya di sekolah yaitu diajarkan melalui pendidikan agama. Pendidikan Agama dimaksudkan untuk peningkatan potensi spritual dan membentuk peserta didik agar menjadi manusia yang beriman dan bertakwa kepada Tuhan Yang Maha Esa dan berakhlak mulia. Akhlak mulia yang mencakup etika, budi pekerti yang luhur, dan moral sebagai perwujudan dari pendidikan agama.

${ }^{14}$ Fahrudin, Proses Pendidikan Moral di Lingkungan Keluarga sebagai Upaya Mengatasi Kenalakan Remaja (Jurnal Pendidikan Agama Islam Ta'lim. vol.12. no. 1 2014), hal.53. 
Dari permasalahan mengenai moral yang merambah pada masa di mana seseorang itu perlu didikan yang dapat dijadikan sebagai panutan dalam berakhlak mulia atau disebut juga berakhlak baik. Dalam Al-Qur'an, surat Al-Ahzab ayat 21, Allah telah menjelaskan:

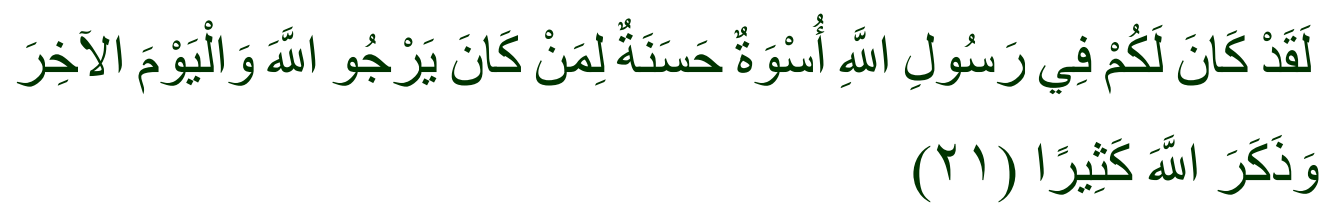

Sesungguhnya Telah ada pada (diri) Rasulullah itu suri teladan yang baik bagimu (yaitu) bagi orang yang mengharap (rahmat) Allah dan (kedatangan) hari kiamat dan dia banyak menyebut Allah. (Q.S. Al-Ahzab, 33: 21)

\section{METODE PENELITIAN}

Metode yang digunakan dalam studi ini menggunakan pendekatan kualitatif dengan desain penelitian study literature. Adapun sumber data berupa jurnal serta buku-buku referensi yang terkait dengan variabel. Jenis data yang digunakan data skunder yaitu diperoleh dari jurnal dan sumber-sumber bacaan yang terkait dengan variabel.

\section{PENUTUP}

Rusaknya moral seseorang anak terjadi karena dua faktor utama. Yang pertama adalah faktor keluarga dan yang kedua adalah faktor lingkungan sosialisasi. Adanya pendidikan moral sangat berperan penting dalam pembentukan generasi muda bangsa guna memiliki nilai-nilai pendidikan yang baik pada lingkungan masyarakat, khususnya lingkungan sekolah. Ini merupakan tugas pendidik menciptakan generasi-generasi bangsa yang baik, berakhlak mulia, dan berbudipekerti sesuai dengan nilai-nilai norma keagamaan. Di antara nilai-nilai yang harus ditanamkan adalah sopan santun, berbudi pekerti, berdisiplin, berhati lapang, berhati lembut, beriman dan bertakwa, berkemauan keras, bersahaja, 
Al-Tarbawi Al-Haditsah: Jurnal Pendidikan Islam

Vol. 3, No. 2, Desember 2018

bertanggung jawab, bertenggang rasa, jujur, mandiri, manusiawi, mencintai ilmu, menghargai karya orang lain, rasa kasih sayang, rasa malu, rasa percaya diri, rela berkorban, rendah hati, sabar, pemaaf, semangat kebersamaan, setia, sportif, taat asas, takut bersalah, tawakal, tegas, tekun, amanah, terbuka, dan ulet. Jadi, dari keterangan yang telah disebutkan tersimpulkan bahwa pendidikian moral berfungsi untuk memagari seseorang dari hal perbuatan buruk atau perbuatan tidak baik yang tidak sesuai dengan norma-norma yang ada dalam pendidikan, bermasyarakat, berbangsa, dan bernegara.

\section{Daftar Pustaka}

Djatnika, Rachmat. 1996. Sistem Ethika Islami (Akhlak Mulia). Bandung: Panjimas

Fahrudin. 2014. Proses Pendidikan Moral di Lingkungan Keluarga sebagai Upaya Mengatasi Kenalakan Remaja. Jurnal Pendidikan Agama Islam Ta'lim, vol.12, no. 1.

Ibda, Fatimah. 2012. Pendidikan Moral Anak Melalui Pengajaran Bidang Studi PPKn dan Pendidikan Agama. Jurnal Ilmiah Didaktika, vol. XII, no.2.

Karabel and Halsey, editors. 1977. Power and Ideology in Education. New York: Oxford University Press

Lickona, Thomas. 2008. Pendidikan Karakter Panduan Lengkap Mendidik Siswa Menjadi Pintar dan Baik. Bandung: Nusa Media

Quasem M., Abul. 1988. Etika Al-Ghazali. Bandung: Penerbit Pustaka

Sjarkawi. 2011. Pembentukan Kepribadian Anak (Peran Moral, Intelektual, Emosional, dan Sosial Sebagai Wujud Integritas Membangun Jati Diri. Jakarta: Bumi Aksara

Undang-Undang RI Nomer 31 Tahun 2003 tentang Undang-undang Sisdiknas dan Undang-undang Guru dan Dosen

Zuchdi, Darmiyati. 2001. Pendekatan Pendidikan Nilai Secara Komprehensif Sebagai Suatu Alternatif Pembentukan Akhlak Bangsa (Makalah Seminar). Yogyakarta: Lembaga Penelitian UNY

Zuchdi, Darmiyati. 2009. Humanisasi Pendidikan (Menemukan kembali Pendidikan yang Manusiawi). Jakarta: Bumi Aksara 